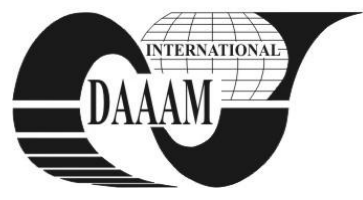

\title{
EXPERT SYSTEM FOR ASSESSING HEALTH HAZARDS OF METALWORKING FLUIDS
}

\author{
MECIAROVA, J[ulia]
}

\begin{abstract}
The major environmental and health hazards in machining operations are due to the use of metalworking fluids. Direct exposure to these fluids can lead to skin diseases and respiratory disorders and there is also an increased risk of cancers. The aim of this paper is to present an expert system that assesses the hazards of metalworking fluids to minimize the risk of exposure. It is developed via specialized software toolshell, which is equipped with an inference mechanism and a knowledge base. The system asks questions of the user to elicit the information needed to assess the hazards and uses IFTHEN rules to represent knowledge. The result is a recommendation for safety using of the metalworking fluids.
\end{abstract}

Key words: expert system, metalworking fluids, health, hazard

\section{INTRODUCTION}

Metalworking fluids (also called cutting fluids) are an important part of machining process. Traditionally, they are evaluated and selected only according to functional requirements and cost performance (Šugár, 2006). But due to the increasing number of laws and directives governing industrial safety and environmental protection, their use is putting intense economic pressure on manufacturing companies because a cutting fluid is an important source of health and environmental hazards (Náprstková \& Holešovský, 2007), (Dado, 2007).

The research has brought four major concerns that have been raised about the application of metalworking fluids. First, particulates, tramp oils and bacteria are known to reduce the quality of metalworking operations over time. Second, these contaminants eventually render the fluid ineffective for metalworking operations, creating significant disposal costs. Third, the disposal of metalworking fluids places a significant burden on the environment and finally, additives used to control their growth can be a significant health hazard (Skerlos, 2000).

Therefore, cutting fluid has become one of important research issues in the field of green manufacturing (Sheng, 1996). Yue (Yue, 2000) proposed a comprehensive model for cutting fluid mist formation in machining, including mechanism of atomization and vaporization. Michigan Technological University developed an Internet-based cutting fluid evaluation software testbed (CFEST) (**), which provides a tool to analyze the environmental impact of cutting fluids in the machining process. However, the software does not work at the given Web page.

The purpose of this paper is to present an expert system that assesses the health hazards of metalworking fluids to minimize the risk to machine operator and the environment.

\section{DEVELOPMENT OF EXPERT SYSTEM}

\subsection{Knowledge-based expert system}

Knowledge-based expert systems, or simply expert systems, use human knowledge to solve problems that normally would require human intelligence.
These systems represent the expertise knowledge as data or rules within the computer. They collect the small fragments of human know-how into a knowledge-base which is used to reason through a problem, using the knowledge that is appropriate. Expert systems can solve a wide range of health issues e.g. (Hanganu, 2009), (Nestorovic, 2010).

Most expert systems are developed via specialized software tools - shells. These shells come equipped with an inference mechanism and require knowledge to be entered according to a specified format. The knowledge base is created of if-then rules and prompts $(* * *)$.

A typical rule-based expert system integrates:

- a problem-domain-specific knowledge base that stores the encoded knowledge to support one problem domain. The knowledge base includes the if-then rules and additional specifications that control the course of the interview,

- an inference engine that implements the reasoning mechanism and controls the interview process,

- the user interface requests information from the user and outputs intermediate and final results. In some expert systems, input is acquired from additional sources such as data bases and sensors.

\subsection{Expert system for assessing metalworking fluids}

For the developmet of expert system, free e2gLite expert system building tool (shell) implemented as a Java applet was applied $(* * *)$.

To use the expert system, a Web page that loads the applet and identifies the knowledge base is needed. The system can be used also without network connection under the requirement for putting the Web page (knowledge.html), the knowledge base (knowledge.kb) and the e2gLite applet archive (e2glite.jar) in the same subdirectory.

By opening the file knowledge.html, the browser (Internet Explorer, Mozilla Firefox, Opera, Google Chrome a.o.) launches the system.

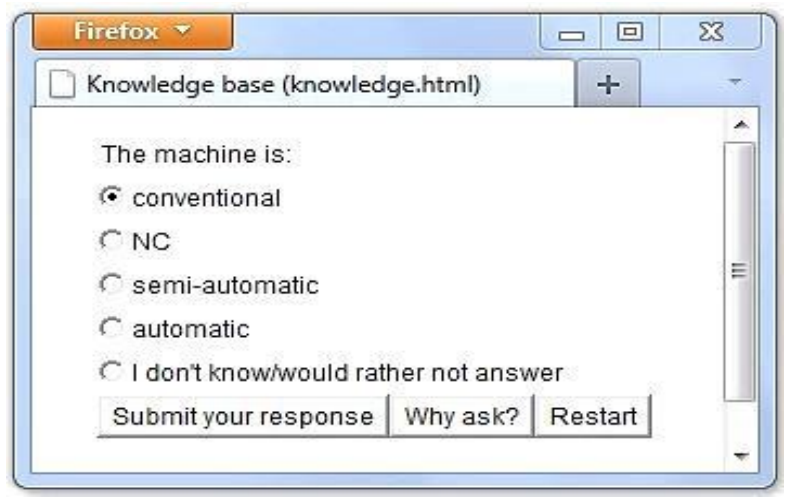

Fig. 1. Question of expert system about the machine

After downloading the knowledge base, the system gives questions to a user (Fig. 1., Fig. 2.). When the user submits his response, he can continue to another question. 


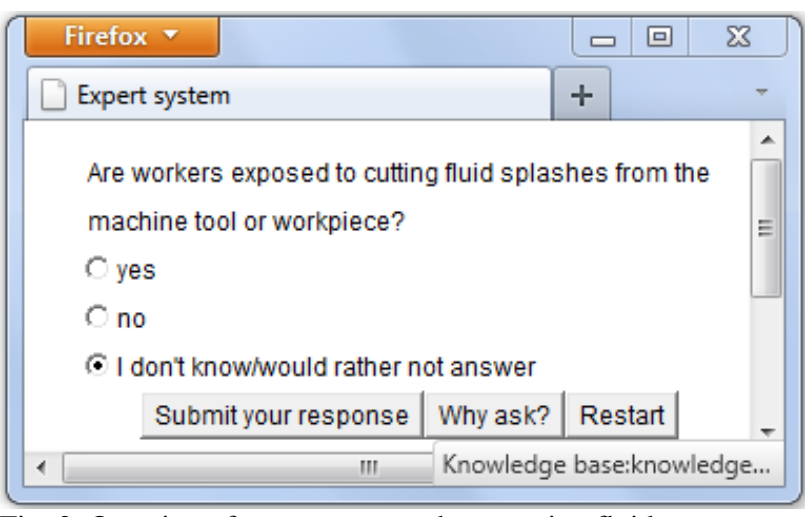

Fig. 2. Question of expert system about cutting fluid exposure

After clicking the "Why ask?" button, the user can see the inference engine's explanation of the question. The user can find out the goal or subgoal, the inference engine is currently working on, attribute that is trying to find and the rule that needs the value of this attribute.

\begin{tabular}{|l|l|l|}
\hline Firefox \\
\hline \begin{tabular}{l}
\hline Eo find [exposure rate] a value for [rotational motion] \\
is needed to try this rule:
\end{tabular} \\
RULE: rule 0 \\
IF: rotational motion is false and \\
machine guard is false and \\
ventilation system is false \\
THEN: exposure rate is low hazard of respiratory diseases \\
A value for: Irotational motion] has not yet been determined \\
Knowledge baseiknowledge...
\end{tabular}

Fig. 3. Explain of the question

After answering the questions, the inference engine has enough information to conclude the interview with exposure rate: hazard of respiratory diseases, eye irritation, skin disorders or sensibilization.

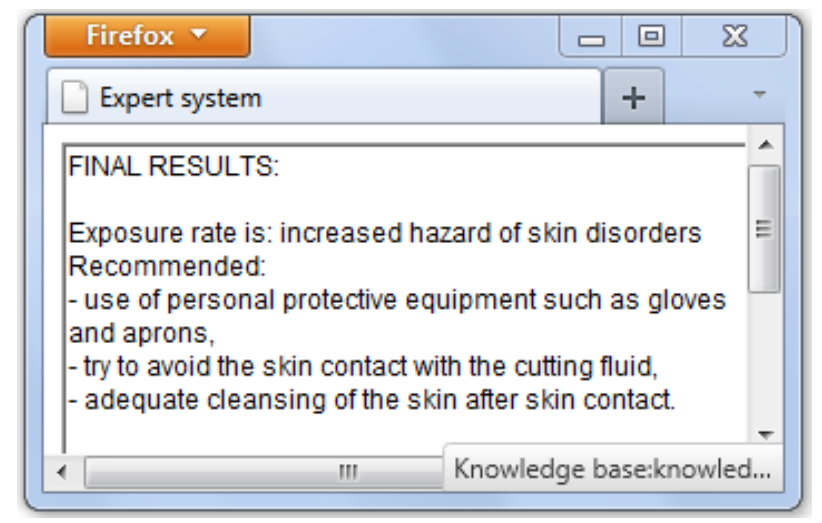

Fig. 4. Final results

Workers can be exposed to metalworking fluids by inhaling aerosols and by skin contact with the fluid. The resulting level of exposure depends on many factors: the type of cutting fluid and its application process, temperature, the specific machining operation, the presence of splash guarding and the effectiveness of the ventilation system in capturing and removing the mist.

Expert system shows the potencial hazards (low, increased or high) and gives recommendations for safety using of the metalworking fluids (e.g. the use of personal protective equipment).

\section{CONCLUSION}

The purpose of this project is to find a solution for computer-aided selection of cutting fluid with respect to health of workers. The present state of the development of expert system for the health assessment of metalworking fluids was presented in this paper. It has a knowledge base created of ifthen rules and prompts, an inference engine and graphical user interface. The system is created in the form of questionnaire, is flexible and easy to use. The result of this expert system is the determination of exposure rate to preserve the occupational safety and give recommendation for safety using of the metalworking fluids. The system is an effective tool how to implement a process-planning strategy for comprehensively integrating health and environmental considerations into traditional metal-cutting operations.

In further research it is necessary to extend the system with questions about the waste streams of cutting fluids and their impact on the environment.

\section{ACKNOWLEDGEMENTS}

The author wishes to thank for the financial support of the Ministry of Education, Science, Research and Sport of the Slovak Republic, in framework of research project VEGA 1/0114/11.

\section{REFERENCES}

Dado, M. (2007). Environmental risks associated with cutting fluids. Manufacturing Technology, Vol.12, No.1, (2007) pp. 33-36, ISSN 1211-4162

Hanganu, S. C. \& Hanganu, L. C. (2009). Knowledge-Based Expert System Applied in Oral Health Towards Tobacco Use Prevention and Smoking Cessation, Annals of DAAAM for 2009 \& Proceedings of the 20th International DAAAM Symposium, 25-28th November 2009, Vienna, Austria, ISSN 1726-9679, ISBN 978-3-901509-70-4, Katalinic, B. (Ed.), pp. 0615-0616

Náprstková, N. \& Holešovský, F. (2007). Process Fluid Flow Measurement at FPTM. Proceedings of the 4th International Congress on Precision Machining, 25-28th September 2007, Sandomierz-Kielce, Poland, ISBN 97883-88906-91-6, pp.165-167.

Nestorovic, T. (2010). Dog Disease Expert System, Annals of DAAAM for 2010 \& Proceedings of the 21st International DAAAM Symposium, 20-23rd October 2010, Zadar, Croatia, ISSN 1726-9679, ISBN 978-3-901509-73-5, Katalinic, B. (Ed.), pp. 1021-1022

Sheng, P. \& M. Srinivasan, M. (1996). A Hierarchical Part Planning Strategy for Environmentally-Conscious Manufacturing, Annals of the CIRP, Vol. 45, No. 1, (1996) pp. $455-460$.

Skerlos, S.J. (2000). Prevention of Metalworking Fluid Pollution: Environmentally Conscious Manufacturing at the Machine Tool. Available from: http://www.umich.edu/ me589/R5_MWF.pdf. Accessed: 2011-03-07

Šugár, P. (2006). Optimization of the cutting fluid selection from the human risks point of view. Acta Mechanica Slovaca, Vol. 2, No. B, (2006), pp. 439 - 442, ISSN 13352393

Yue, Y. (2000). A comprehensive model for cutting fluid mist formation in machining, Ph.D. Thesis, Michigan Technological University, USA

** (2004) http://www.mfg.mtu.edu/testbeds/cfest/casestudy1. html. - Cutting fluid evaluation software testbed (CFEST), Assessed on: 2011-01-15

*** (2006) http://www.expertise2go.com/webesie - Building and Using Expert Systems: a Mini-Course Introducing the e2gLite Expert System Shell, Accessed on: 2010-9-14 